\title{
Pearls in the Evaluation and Treatment of Orbital Cellulitis in Adults
}

\author{
Laura Nuzzolo-Shihadeh and Adrián Camacho-Ortiz* \\ Servicio de Infectología, Dr. José Eleuterio González University Hospital, Universidad Autónoma de Nuevo León, Monterrey, N.L., Mexico
}

\begin{abstract}
Orbital cellulitis is a condition that represents the main infection of ocular adnexa and orbital tissues. Clinical criteria and tomographic data allow classification of the condition for correct treatment to avoid complications and permanent sequelae, mainly for the patient's vision. It requires adequate and multidisciplinary intervention from the beginning, and it is important to take into consideration that the treatment must consist of systemic antibiotics in all cases and depending on the situation, surgical procedures may be required. The primary management in the treatment should provide an appropriate empirical antibiotic therapy that gives coverage against the most frequently involved microorganisms. It should be started as soon as possible and modified, if necessary, based on the interpretation of the Gram stain, the culture, and the susceptibility of the isolated microorganism.
\end{abstract}

Key words: Orbital cellulitis. Preseptal cellulitis. Streptococcus pyogenes. Staphylococcus aureus.

Orbital cellulitis is a condition that represents the main infection of ocular adnexa and orbital tissues'. Clinical criteria and tomographic data allow classification of the condition for correct treatment to avoid complications and permanent sequelae, mainly for the patient's vision?

The term "preseptal cellulitis" is used to characterize the cellulitis of the tissue located anterior to the orbital septum. In contrast, the term "orbital cellulitis" is used to describe infections involving tissue posterior to the orbital septum, including the eyeball, muscles, adipose tissue, and bone of the orbit ${ }^{3}$.

The distinction of these entities is important, since, although orbital cellulitis is less frequent, it can be associated with visual sequelae and life-threatening conditions. These can include optic neuropathy, meningitis, cavernous sinus thrombosis, intracranial abscesses, and sepsis ${ }^{4}$. On the other hand, complications of preseptal cellulitis are local, such as ectropion, subacute lid abscesses, eyelid necrosis, and lagophthalmos, which are rare, and develop, especially if the condition is not treated early during the course of the infection ${ }^{5}$.

Clinical history and a physical examination are determinants in the diagnosis of these conditions. The presence of comorbidities such as diabetes, psoriasis, and other immunodeficiencies acts as predisposing factors $^{6}$. Commonly, this entity can be associated with a recent sinus infection. However, it is important to consider a history of facial trauma, surgery, and dental procedures as risk factors ${ }^{7}$.

During the ophthalmologic examination, it is essential to evaluate extrinsic ocular motility, the presence of a

\section{Correspondence:}

*Adrián Camacho-Ortiz

E-mail: acamacho_md@yahoo.com
Date of reception: 14-08-2018

Date of acceptance: 25-10-2018

DOI: 10.24875/RMU.M18000026
Available online: $30-11-2018$ Medicina Universitaria. 2018;20(3):140-142 www.medicinauniversitaria.org

1665-5796/@ 2018 Universidad Autónoma de Nuevo León. Published by Permanyer México SA de CV. This is an open access article under the CC BY-NC-ND license (http://creativecommons.org/licenses/by-nc-nd/4.0/). 
pupillary reflex and signs of meningeal irritation. Both preseptal and orbital cellulitis shared some clinical signs and symptoms, such as edema, erythema, and increased local temperature surrounding the eyelid, but in general, these are two different and independent processes. Ophthalmoplegia, proptosis and decreased visual acuity are specific clinical manifestations of orbital cellulitis that are not found in patients with preseptal cellulitis. Fever and leukocytosis can occur in both cases, although their presence is more common in orbital cellulitis ${ }^{8}$. The clinical findings may not be specific enough to distinguish preseptal from orbital infections and their complications. Therefore, whenever orbital cellulitis is suspected, the use of contrast computed tomography, or magnetic resonance imaging could demarcate the extension of the infection, determine the presence of abscesses, reveal any sinus diseases, and identify intracranial complications (Fig. 1) . $^{9}$ Orbital cellulitis requires adequate and multidisciplinary intervention from the beginning, and it is important to take into consideration that the treatment must consist of systemic antibiotics in all cases and depending on the situation, surgical procedures may be required ${ }^{10}$.

The microorganisms most commonly involved in the pathogenesis of these entities are Staphylococcus aureus followed by Streptococcus pyogenes. The clinical findings could be decisive in the presumption of the etiology, taking into consideration that $S$. aureus infections tend to develop abscesses ${ }^{11}$, whereas in $S$. pyogenes infections, diffuse edema, and erythema of the tissue are the most common presentation. The incidence of orbital cellulitis due to community-acquired methicillin-resistant $S$. aureus (MRSA) and hospital-associated MRSA is increasing, and empirical treatment should be directed against this microorganism, if it is prevalent in the region ${ }^{12}$. Therefore, certain predisposing factors must be taken into consideration (Table 1) ${ }^{13}$. The primary differential diagnoses to contemplate in diabetic and neutropenic patients should be mucormycosis. In addition, allergic reactions, dermoid cyst rupture, skin metastases, chronic intranasal cocaine abuse, and neutrophilic eccrine hidradenitis should be taken into consideration ${ }^{14}$

The initial management in the treatment of both preseptal and orbital cellulitis should provide an appropriate empirical antibiotic therapy that gives coverage against the most frequently involved microorganisms. It should be started as soon as possible and modified, if necessary, based on the interpretation of a gram stain, the culture results, and the susceptibility of the isolated microorganism (Table 2$)^{3}$.
Table 1. MRSA risk factors.

\begin{tabular}{|l|l|}
\hline Risk factors for CA-MRSA & Risk factors for HA-MRSA \\
\hline Contact sports & $\begin{array}{l}\text { Recent hospitalizations } \\
\text { (6 months prior) }\end{array}$ \\
\hline $\begin{array}{l}\text { Sharing towels or sports } \\
\text { equipment }\end{array}$ & $\begin{array}{l}\text { Invasive procedures such as } \\
\text { bladder catheters, arterial line, or } \\
\text { central venous lines }\end{array}$ \\
\hline Visiting gyms frequently & $\begin{array}{l}\text { Recent use of antibiotics } \\
\text { (6 months prior) }\end{array}$ \\
\hline Intravenous drug use & $\begin{array}{l}\text { Regular contact with healthcare } \\
\text { workers }\end{array}$ \\
\hline $\begin{array}{l}\text { Living in overcrowded } \\
\text { conditions }\end{array}$ & Chronic dialysis \\
\hline
\end{tabular}

CA-MRSA: community-acquired methicillin-resistant $S$. aureus, HA-MRSA: hospital-associated methicillin-resistant $S$. aureus, S. aureus: Staphylococcus aureus.

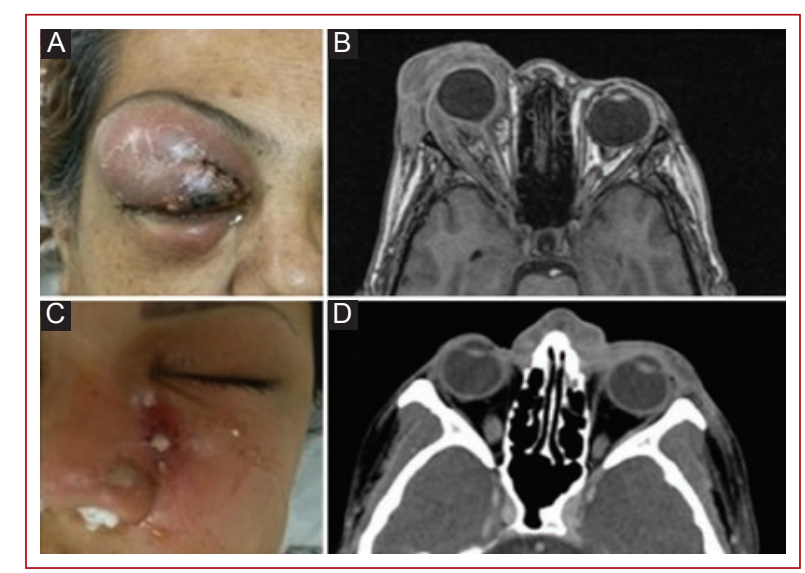

Figure 1. (A) A clinical photograph demonstrating a right orbital cellulitis with redness and proptosis. (B) Magnetic resonance imaging of the same patient demonstrating eyelid abscess, proptosis, and extraconal soft tissue mass. (C) A clinical photograph demonstrating a left preseptal cellulitis with redness and edema.

(D) Computed tomography scan of the same patient demonstrating diffuse soft tissue thickening and areas of enhancement anterior to the orbital septum.

The early and multidisciplinary approach is imperative. Therefore, actions such as early drainage of abscesses and identification of risk factors for MRSA infections are decisive. It is important to consider that beta-lactams should be adopted as the first treatment option. Nevertheless, aspects such as allergies, renal function and the severity of the clinical presentation are also relevant and should be taken into account from the initial approach of the patient with both preseptal and orbital cellulitis. 
Table 2. Empirical treatment regimens in preseptal and orbital cellulitis.

Suspected $S$. aureus infection without shock

Trimethoprim/sulfamethoxazole $8-20 \mathrm{mg} / \mathrm{kg} / \mathrm{day}$ q 12 h IV or

Clindamycin $600-900 \mathrm{mg}$ IV q8 h or

Linezolid $600 \mathrm{mg}$ IV $\mathrm{q} 12 \mathrm{~h}$ or

Tigecycline $100 \mathrm{mg}$ IV load dose, then $50 \mathrm{mg}$ IV q12 $\mathrm{h}$

Suspected MRSA infection accompanied by signs of shock

Vancomycin $20 \mathrm{mg} / \mathrm{kg}$ load dose, then $15-20 \mathrm{mg} / \mathrm{kg} \mathrm{IV} \mathrm{q12} \mathrm{h} \pm$ Clindamycin* 600-900 mg IV q8 h or

Ceftaroline $600 \mathrm{mg}$ IV q8 h

\section{Suspected S. pyogenes infection without shock}

Penicillin $\mathrm{G} 4$ million units IV q4-6 h or

Clindamycin* 600-900 mg IV q8 h or

Ceftriaxone** $1 \mathrm{~g} \mathrm{IV} \mathrm{q24} \mathrm{h}$

\section{Suspected $S$. pyogenes infection accompanied by shock}

Penicillin G 4 million units IV q4-6h or

Ceftriaxone $2 \mathrm{~g}$ IV q24 $\mathrm{h}+$

Clindamycin* $600-900 \mathrm{mg}$ IV q8 $\mathrm{h}$ or

Linezolid* $600 \mathrm{mg}$ IV q12 h

Orbital cellulitis in neutropenic patients also consider $\boldsymbol{P}$. aeruginosa.

Vancomycin $20 \mathrm{mg} / \mathrm{kg}$ load dose, then $15-20 \mathrm{mg} / \mathrm{kg}$ IV q12 h

+: piperacillin-tazobactam $4.5 \mathrm{~g}$ IV q6 $\mathrm{h}$

or meropenem $2 \mathrm{~g}$ IV q8 $\mathrm{h}^{* * *}$

*Used for toxin inhibition,

** In case of penicillin allergies,

*** In case of suspected extended-spectrum beta-lactamase producing $P$. aeruginosa

$S$. pyogenes: Streptococcus pyogenes, $P$. aeruginosa: Pseudomonas aeruginosa.

\section{Ethical disclosures}

The authors declare and guarantee that they have a document signed by the patients whose images are included in the article, authorizing the inclusion of said data in the document above and its subsequent editions, distribution, and dissemination, both nationally and internationally, on platforms and computer networks that Revista de MEDICINA UNIVERSITARIA uses. This document is in possession of the correspondence author.

Protection of human and animal subjects. The authors declare that no experiments were performed on humans or animals for this study.

Confidentiality of data. The authors declare that they have followed the protocols of their work center on the publication of patient data.

Right to privacy and informed consent. The authors have obtained the written informed consent of the patients or subjects mentioned in the article. The corresponding author is in possession of this document.

\section{References}

1. Farrell L, Ezpeleta M, Sierra C, Mayer F. Celulitis orbitaria bilateral con endoftalmitis en una paciente con reciente diagnóstico de diabetes mellitus tipo 2. Rev Mex Oftalmol. 2014:88:146-51.

2. Babar T, Zaman M, Khan M, Khan M. Risk factors of preseptal and orbital cellulitis. J Coll Physicians Surg Pak. 2009;19:39-42.

3. Lee S, Yen M. Management of preseptal and orbital cellulitis. Saudi Coll Ophthalmol. 2011;24:21-9.

4. Liu T, Kao S, Wang A, Tsai C, Liang C, Hsu W. Preseptal and orbital cellulitis: a 10-year review of hospitalized patients. J Chin Med Assoc. 2006;69:415-22.

5. Chaudhry IA, Shamsi FA, Elzaridi E, et al. Inpatient preseptal cellulitis: experience from a tertiary eye care centre. Br J Ophthalmol. 2008:92:1337.

6. Llop M, Martínez-Roig A. Enfermedades bacterianas de la piel. Pediatr Integral. 2012;36:235-43

7. Grimes D, Fan K, Huppa C. Case report: dental infection leading to orbital cellulitis. Dent Update. 2006;33:217-20.

8. Gimeno I, Rojo P. Celulitis preseptal y orbitaria. Ann Pediatr Contin. 2014;12:284-8.

9. Rudloe T, Harper M, Prabhu S, Rahbar R, Veen D, Kimia A. Acute periorbital infections: who needs emergent imaging? Pediatrics. 2010; 125:e719-26.

10. Péreza M, Castro G, Mansillac C, et al. Celulitis orbitaria por Staphylococcus aureus meticilinorresistente de la comunidad. Arch Argent Pediatr. 2012;110:e9-12.

11. Cheng A, DeDent A, Schneewind O, Missiakas D. A play in four acts: Staphylococcus aureus abscess formation. Trends Microbiol. 2011:19:225-32.

12. McKinley S, Yen M, Miller A, Yen K. Microbiology of pediatric orbital cellulitis. Am J Ophthal. 2007;144:497-501.

13. Zeller J, Golub R. Infecciones por MRSA. JAMA. 2011:206:16.

14. Choi VL, Yuen H, Biswas J, Yanoff M. Update in pathological diagnosis or orbital infections and inflammations. Middle East Afr J Ophthalmol. 2011:18:268-76. 